\title{
Inflammatory markers in patients with internal carotid artery stenosis
}

\author{
Przemysław Puz ${ }^{1}$, Anetta Lasek-Bal', Damian Ziaja², Zofia Kazibutowska², Krzysztof Ziaja²
}

1Stroke Department, Medical Centre of Silesia, Katowice, Poland

2Department of General and Vascular Surgery, Medical University of Silesia, Katowice, Poland

Submitted: 30 March 2012

Accepted: 11 July 2012

Arch Med Sci 2013; 9, 2: 254-260

DOI: 10.5114/aoms.2013.34533

Copyright @ 2013 Termedia \& Banach

\section{Abstract}

Introduction: Available reports underline the significance of the inflammatory process in the development, progression and destabilisation of atherosclerotic plaques in the internal carotid artery (ICA). The aim of this study was to evaluate the relationship between the degree of ICA stenosis, ultrasound plaque morphology and serum concentration of selected inflammatory markers.

Material and methods: Sixty-five patients with ICA stenosis > 50\% (39 symptomatic) and 30 healthy volunteers were enrolled in the study. Clinical, neurological examination and laboratory evaluation (leucocyte count, erythrocyte sedimentation rate (ESR), C-reactive protein (CRP), fibrinogen, tumour necrosis factor- $\alpha$ (TNF- $\alpha$ ), interleukins ( $1 \beta, 6$ and 10), anti-cytomegalovirus IgG antibody titre) were performed. Stenosis grade $\geq 70 \%$, ulcerations on the plaque surface and a hypoechoic (or predominantly hypoechoic) structure of the plaque, obtained by colour-coded duplex examination, were accepted as the characteristics of unstable stenoses.

Results: Unstable ultrasound features of ICA stenosis were found significantly more often in symptomatic than in asymptomatic patients $(71.79 \%$ vs. $30.71 \%$ for stenosis degree $\geq 70 \%, p=0.001$ and $61.23 \%$ vs. $38.46 \%$ for unstable plaque morphology, $p=0.01$ ). Patients with ICA stenosis had significantly higher serum concentrations of interleukin-6, fibrinogen, ESR and higher CRP values than the individuals from the control group ( $p=0.001, p=0.009, p=0.036, p=0.009$ respectively). Patients with unstable plaques structure had significantly higher concentrations of TNF- $\alpha$, interleukin-6, fibrinogen, higher number of leukocytes, monocytes and higher CRP values than patients with stable plaques ( $p=0.008, p=0.049, p=0.012, p=0.0002, p=0.006, p=0.0003$ respectively). No significant differences in above-mentioned parameters between the groups with stenosis $<70 \%$ and $\geq 70 \%$ were found.

Conclusions: There is a relationship between the activity of the selected inflammatory markers in serum and atherosclerotic unstable internal carotid artery stenosis. There is no relationship between serum concentration of inflammatory markers and degree of carotid artery stenosis.

Key words: atherosclerosis, artery stenosis, inflammatory markers.

\section{Introduction}

In patients with atherosclerotic internal carotid artery (ICA) stenosis, the degree of the stenosis and the structure of the plaque are the most important risk factors for brain ischaemia [1-3]. The ultrasound characteristics identifying an unstable plaque are hypoechogenicity or hetero-

\author{
Corresponding author: \\ Przemysław Puz MD, PhD \\ Stroke Department \\ Medical Centre of Silesia \\ 45 Ziołowa St \\ 40-635 Katowice, Poland \\ Phone: +48602621822 \\ E-mail: ppuz@tlen.pl
}


genicity with the dominance of hypoechogenic lesions and ulceration of the surface. Plaques with a smooth surface, with a high amount of calcification are considered to be stable $[1,2,4,5]$.

Numerous publications from recent years indicate a significant contribution of inflammatory factors to the development, progression and destabilisation of atherosclerosis [6-14]. Atherosclerotic lesions in the carotid arteries have been associated with increased serum levels of different inflammatory markers, i.e. C-reactive protein (CRP) and fibrinogen [9-12, 15]. The cells of the atherosclerotic plaque are a source of cytokines acting locally and systemically $[6,8,15]$. The basic proinflammatory cytokines include TNF- $\alpha$ (TNF- $\alpha$ ), interleukin$1 \beta$ (IL-1 $\beta$ ), and interleukin-6 (IL-6) [6-8, 14-16]. Interleukin-10 (IL-10) is one of the most important mediators limiting inflammatory processes within the atherosclerotic plaque $[6,17]$. The factors determining the destabilisation of the atherosclerotic plaque also include infection and the immunological response that is associated with it $[6,8]$. The balance of the interaction between proand anti-inflammatory factors within atherosclerotic plaques seems to determine the dynamics of the disease.

The aim of the study was to evaluate in patients with internal carotid artery stenosis the relationship between atherosclerotic plaque morphology, the degree of stenosis and serum concentration of selected inflammatory markers.

\section{Material and methods}

\section{Material}

The study included 65 patients (20 women, 45 men) aged 55-80 years (mean: 66.29; SD: 7.77 ) with ICA stenosis $\geq 50 \%$ and 30 individuals from the control group (20 women, 10 men) aged 50-78 years (mean: 61.03; SD: 9.08). The remaining criteria of inclusion in the study group were: a neuroimaging examination (CT or $\mathrm{MRI}$ ) excluding the non-vascular brain damage, and the patient's informed consent to participation in the study. The exclusion criteria were: stenosis with a cause other than atherosclerosis, a recent infection (found on the basis of a physical examination and laboratory tests), acute or chronic renal failure, a documented liver disease, a neurological disease except for symptoms caused by atherosclerotic ICA stenosis, a recent stroke (up to 14 days after the occurrence of the symptoms), cardiac arrhythmia, a recent myocardial infarction, a haemodynamically significant valvular heart disease, the presence of an artificial heart valve, a neoplastic disease, advanced circulatory insufficiency (NYHA class III or IV), alcohol abuse, a haematological and connective tissue disease and chronic inflammatory bowel disease, pancreatitis, an injury or surgical procedure in the period of 6 months before assaying the concentration of inflammation markers, hormonal disturbances (thyroid gland or gonad function disturbances), and steroid therapy.

Symptomatic ICA stenosis, which was the cause of a stroke or a transient ischaemic attack, was found in 39 patients. The control group consisted of 30 healthy volunteers or patients treated at the Neurology Department due to dizziness (9 individuals), headaches (5 individuals), or pain in the cervical or lumbosacral spine (14 individuals), who met the exclusion criteria and in whom stenosis of the cerebral arteries was excluded. All of them were informed of the aim and course of the study and expressed informed consent to it. The consent of the Ethics Committee of the Medical University of Silesia to conduct the study was obtained (Consent No. NN-6501-90/I/05).

\section{Laboratory tests}

The following laboratory tests were carried out in all included individuals: leucocyte count, erythrocyte sedimentation rate (ESR), CRP, fibrinogen, TNF- $\alpha$, interleukins ( $1 \beta, 6$ and 10), anti-cytomegalovirus (CMV) IgG antibody titre; the concentration of procalcitonin was additionally assayed in patients with carotid artery stenosis.

The level of CRP was assayed using the immunoturbidimetric method with a cut-off point of $5.0 \mathrm{mg} / \mathrm{l}$. Values of CRP below $5 \mathrm{mg} / \mathrm{l}$ were assessed as a negative result and such a result was considered to be normal. Fibrinogen concentration was assayed using the modified Clauss method. The range of reference values was 1.8-3.5 g/l.

Blood for TNF- $\alpha$, IL-1 $\beta$, IL-6, IL-10, procalcitonin and anti-CMV IgG tests was collected in patients in a fasting state. The blood was centrifuged at the speed of $3500 \mathrm{rpm}$ for $15 \mathrm{~min}$ at room temperature, and the obtained serum samples were immediately frozen and stored until the moment of performing the assays. Assays of the serum concentrations of TNF- $\alpha$, IL-1 $1 \beta$, IL- 6 and IL-10 were carried out in duplicate using the following enzyme immunoassay (EIA) kits manufactured by Rai Biotach: Human IL-1 ELISA kit, Human IL-6 ELISA kit, Human IL-10 ELISA kit, Human TNF- $\alpha$ ELISA kit. The obtained absorbance values were read at a wavelength of $450 \mathrm{~nm}$ using a Sirio $S$ spectrometer. Procalcitonin tests were carried out with the B.R.A.H.M.S PCT LIA I immunoluminometric assay (ILMA). Anti-CMV IgG assays were carried out individually, using Citomegalovirus IgG EIA kits manufactured by RADIM.

In patients with symptomatic stenosis, the first laboratory tests were conducted within 15-154 days (mean: 75.28; median: 86 days) of the occurrence of transient ischaemic attack or stroke. 


\section{Ultrasound examination of carotid arteries}

The examination was performed with a 3.75 $12 \mathrm{MHz}$ linear array transducer of a PHILIPS ENVISOR HD C.O.2 unit using the duplex method and complemented by colour Doppler imaging. The degree of ICA stenosis was evaluated on the basis of planimetric measurements (the diameter of the stenosis in the longitudinal plane and the area of the cross section of the stenosis in the transverse plane) and according to Doppler criteria based on the measurement of blood flow velocity at the level of the stenosis and in the common carotid artery below the stenosis $[18,19]$. The assessment of morphology of plaques constricting the ICA was conducted on the basis of their echogenicity on grey-scale images according to the Gray-Weale classification $[2,20]$ : type 1 - uniformly hypoechoic, type 2 - predominantly hypoechoic, type 3 - predominantly hyperechoic, type 4 - uniformly hyperechoic, type 5 - with calcifications causing acoustic shadowing artefacts.

The following were accepted as the characteristics of unstable stenoses in ultrasound image: stenosis $\geq 70 \%$, presence of ulcerations on the surface of the plaque and a hypoechoic (or predominantly hypoechoic) structure of the atherosclerotic plaque in accordance with the accepted definition of unstable plaques $[1,2,18]$.

\section{Statistical analysis}

The level of statistical significance $p<0.05$ was chosen. Basic statistical parameters (mean, median, standard deviation, minimum and maximum values) were calculated for interval-scale variables (TNF- $\alpha$, IL-1 $\beta$, IL-6, IL-10, fibrinogen, procalcitonin, ESR, leukocyte count, monocyte count, anti-CMV IgG antibody titre). For nominal variables (CRP), frequency and percentage distributions with respect to the categories of these variables were determined. The comparisons of mean/median values in the case of interval-scale variables were made using Student's t-test or the Mann-Whitney $U$ test. The comparisons in the case of groups of nominal variables were made using the $\chi^{2}$ test or Fisher's test, depending on the size of the groups. The correlations between continuous variables were presented, calculating Spearman's rank correlation coefficient and its level of statistical significance.

The obtained results were compared between the study and control groups and within the study group, between patients with symptomatic and asymptomatic internal carotid artery stenosis.

\section{Results}

Stenosis $\geq 70 \%$ was found in $8(30.71 \%)$ patients with asymptomatic stenosis and $28(71.79 \%)$ patients with symptomatic stenosis $\left(p=0.001, \chi^{2}\right.$ test). An unstable morphology of the plaque (with the presence of ulcerations and/or a hypoechoic or predominantly hypoechoic structure of the plaque) was found in 10 (38.46\%) patients with asymptomatic stenosis and 27 (61.23\%) patients with symptomatic stenosis ( $p=0.01, \chi^{2}$ test). Plaques with an unstable morphology were described in 13 (44.83\%) patients with stenosis below $70 \%$ and in $24(66.67 \%)$ patients with stenosis $\geq 70 \%(p=0.08$, $\chi^{2}$ test).

Patients with ICA stenosis, in comparison with the individuals from the control group, had significantly higher serum concentrations of IL-6 (13.65 $\pm 14.46 \mathrm{pg} / \mathrm{ml}$ vs. $5.86 \pm 3.04 \mathrm{pg} / \mathrm{ml}, p=0.001)$, fib rinogen $(3.49 \pm 0.72 \mathrm{~g} / \mathrm{l}$ vs. $2.99 \pm 0.69 \mathrm{~g} / \mathrm{l}, p=0.009)$ and higher ESR values (14.31 \pm 7.17 vs. $10.7 \pm 4.62$, $p=0.036$ ) (Table I, Figure 1).

Increased CRP values (> $5 \mathrm{mg} / \mathrm{l}$ ) were found in 17 patients $(26.15 \%)$ with ICA stenosis. In the control group, no elevated CRP values were observed - these differences were statistically significant ( $p=0.009$, Fisher's test).

In patients with symptomatic stenosis, in comparison with patients with asymptomatic stenosis, significantly higher leukocyte $(7.7 \pm 2.0 \mathrm{G} / \mathrm{l}$ vs. 6.36 $\pm 1.76 \mathrm{G} / \mathrm{l}, p=0.002)$ and monocyte counts (0.66

Table I. Inflammatory factors in patients with ICA stenosis and in the control group

\begin{tabular}{|c|c|c|c|}
\hline Inflammatory factor & ICA stenosis group & Control group & Value of $p$ \\
\hline TNF- $\alpha[p g / m l]$ & $14.32 \pm 6.08$ & $11.78 \pm 5.45$ & $0.055^{*}$ \\
\hline IL-6 [pg/ml] & $13.65 \pm 14.46$ & $5.86 \pm 3.04$ & $0.001^{\star \star}$ \\
\hline IL-10 [pg/ml] & $3.75 \pm 3.55$ & $3.18 \pm 2.48$ & $0.61^{\star *}$ \\
\hline IL-1 $1 \beta$ [pg/ml] & $1.64 \pm 0.64$ & $1.6 \pm 0.45$ & $0.62^{\star *}$ \\
\hline CMV IgG [RU/ml] & $95.86 \pm 74.13$ & $71.34 \pm 56.73$ & $0.18^{\star *}$ \\
\hline Leukocytes [G/l] & $7.16 \pm 2.01$ & $6.44 \pm 1.35$ & $0.18^{\star *}$ \\
\hline Monocytes [G/I] & $0.6 \pm 0.25$ & $0.61 \pm 0.19$ & $0.56^{\star \star}$ \\
\hline ESR & $14.31 \pm 7.17$ & $10.7 \pm 4.62$ & $0.036^{* *}$ \\
\hline Fibrinogen $[\mathrm{g} / \mathrm{l}]$ & $3.49 \pm 0.72$ & $2.99 \pm 0.69$ & $0.009^{*}$ \\
\hline
\end{tabular}

Results presented as mean value $\pm S D$, *Student's $t$-test, ${ }^{* *}$ Mann-Whitney $U$ test 
$\pm 0.28 \mathrm{G} / \mathrm{l}$ vs. $0.52 \pm 0.17 \mathrm{G} / \mathrm{l}, p=0.025)$ were found (Table II).

Elevated CRP values ( $>5 \mathrm{mg} / \mathrm{l}$ ) were found in 12 patients with symptomatic stenosis (30.77\%) and in 5 patients with asymptomatic stenosis $(19.23 \%)$ - these differences were statistically insignificant ( $p=0.29, \chi^{2}$ test).

No statistically significant differences regarding the studied inflammatory markers between the group of patients with stenosis $<70 \%$ and the group with stenosis $\geq 70 \%$ were found. Elevated CRP values ( $>5 \mathrm{mg} / \mathrm{l})$ were found in 6 patients with stenosis $<70 \%(20.69 \%)$ and in 11 patients with stenosis $\geq 70 \%$ (30.56\%) - these differences were statistically insignificant ( $p=0.37, \chi^{2}$ test).

In patients with unstable plaques in the ultrasound image in comparison with patients with stable plaques, significantly higher concentrations of TNF- $\alpha(16.06 \pm 6.12 \mathrm{pg} / \mathrm{ml}$ vs. $12.08 \pm 5.34 \mathrm{pg} / \mathrm{ml}$, $p=0.008)$, IL $-6(15.63 \pm 14.94 \mathrm{pg} / \mathrm{ml}$ vs. $11.03 \pm 13.62$ $\mathrm{pg} / \mathrm{ml}, p=0.049)$, fibrinogen (3.68 $\pm 0.75 \mathrm{~g} / \mathrm{l}$ vs. 3.24 $\pm 0.73 \mathrm{~g} / \mathrm{l}, p=0.012)$ and a higher number of leukocytes (7.92 $\pm 2.16 \mathrm{G} / \mathrm{l}$ vs. $6.17 \pm 1.24 \mathrm{G} / \mathrm{l}, p=0.0002)$ and monocytes $(0.68 \pm 0.28 \mathrm{G} / \mathrm{l}$ vs. $0.49 \pm 0.16 \mathrm{G} / \mathrm{l}$, $p=0.006$ ) were found (Table III, Figure 2).

Elevated CRP values ( $>5 \mathrm{mg} / \mathrm{l}$ ) were found significantly more often in patients with unstable (43.24\%) in comparison with patients with plaques with a stable morphology $(3.4 \%)(p=0.0003$, Fisher's test).

In the group of patients with symptomatic stenosis, no significant correlation was found between the time that had passed since the symptoms and the concentration of TNF- $\alpha(p=0.29)$, IL-6 $(p=0.78)$, IL-10 ( $p=0.56)$, IL-1 $\beta(p=0.06)$, procalcitonin $(p=0.9)$ or anti-CMV IgG antibody titre $(p=0.3)$.

\section{Discussion}

Numerous reports underline the significance of inflammation in the development, progression and

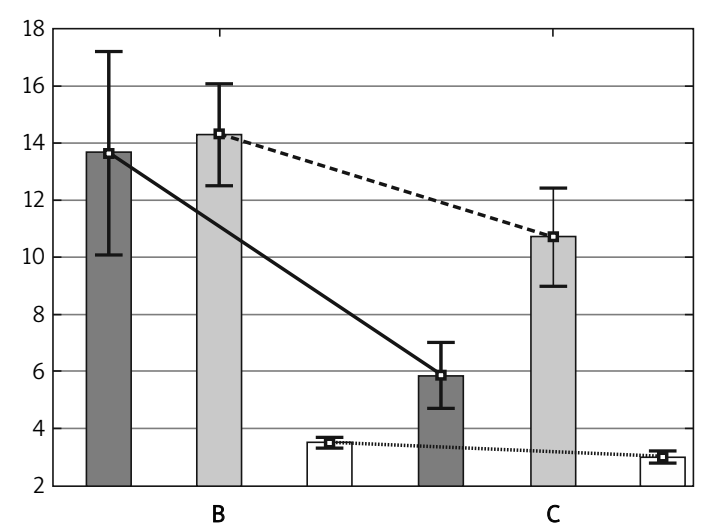

Group (B - patients with ICA stenosis, $C$ - control)

IL-6 [pg/ml] $\quad-\mathrm{E}$ ESR [mm/h] $\square$ Fibrinogen [g/l]

Figure 1. Interleukin-6, ESR and fibrinogen in the group with ICA stenosis and in the control group

destabilisation of atherosclerotic lesions [6, 8-12, 15-17]. In the present study, a significant relationship between elevated values of inflammatory markers in patients with ICA stenosis with unstable atherosclerotic plaques was confirmed but no significant relationships between inflammatory markers and the degree of ICA stenosis were found. The activity of inflammatory factors may indicate changes within atherosclerotic plaques conducive to their destabilisation and as a consequence of an increase in the level of stenosis, and not directly the presence of high-grade stenoses.

Most published reports evaluating the significance of TNF- $\alpha$, IL- $6, I L-1 \beta$ and IL-10 in the development of atherosclerosis are based on studies of coronary arteries [14, 16, 21, 22]. Only some of them concern their participation in the development of atherosclerotic ICA stenosis [7, 8, 13, 15, 23-26].

Significantly higher serum concentrations of IL-6 and TNF- $\alpha$ were found in patients with unstable

Table II. Inflammatory factors in patients with symptomatic and asymptomatic ICA stenosis

\begin{tabular}{|c|c|c|c|}
\hline Inflammatory factor & Symptomatic stenosis & Asymptomatic stenosis & Value of $p$ \\
\hline TNF- $\alpha[p g / m l]$ & $14.58 \pm 6.54$ & $13.93 \pm 5.45$ & $0.67^{\star}$ \\
\hline $\mathrm{IL}-6[\mathrm{pg} / \mathrm{ml}]$ & $13.84 \pm 16.33$ & $13.35 \pm 11.4$ & $0.3^{* \star}$ \\
\hline IL-10 [pg/ml] & $3.56 \pm 3.89$ & $4.03 \pm 3.02$ & $0.3^{* *}$ \\
\hline IL-1 $\beta[\mathrm{pg} / \mathrm{ml}]$ & $1.55 \pm 0.36$ & $1.78 \pm 0.92$ & $0.65^{\star \star}$ \\
\hline Procalcitonin [ng/ml] & $0.32 \pm 0.49$ & $0.15 \pm 0.15$ & $0.76^{\star \star}$ \\
\hline CMV IgG [RU/ml] & $83.5 \pm 68.59$ & $114.39 \pm 79.52$ & $0.16^{\star *}$ \\
\hline Leukocytes [G/I] & $7.70 \pm 2.0$ & $6.36 \pm 1.76$ & $0.002^{* *}$ \\
\hline Monocytes [G/I] & $0.66 \pm 0.28$ & $0.52 \pm 0.17$ & $0.025^{\star *}$ \\
\hline ESR & $14.33 \pm 7.56$ & $14.27 \pm 6.67$ & $0.96^{\star \star}$ \\
\hline Fibrinogen $[\mathrm{g} / \mathrm{l}]$ & $3.57 \pm 0.69$ & $3.37 \pm 0.65$ & $0.29^{*}$ \\
\hline
\end{tabular}

Results presented as mean value $\pm S D$, *Student's t-test, ${ }^{* *}$ Mann-Whitney $U$ test 
Table III. Inflammatory factors and atherosclerotic plaque morphology

\begin{tabular}{|lccc|}
\hline Inflammatory factor & Stable plaque & Unstable plaque & Value of $p$ \\
\hline TNF- $\alpha[\mathrm{pg} / \mathrm{ml}]$ & $12.08 \pm 5.34$ & $16.06 \pm 6.12$ & $0.008^{\star}$ \\
\hline $\mathrm{IL}-6[\mathrm{pg} / \mathrm{ml}]$ & $11.03 \pm 13.62$ & $15.63 \pm 14.94$ & $0.049^{\star *}$ \\
\hline $\mathrm{IL}-10[\mathrm{pg} / \mathrm{ml}]$ & $3.99 \pm 4.6$ & $3.58 \pm 2.55$ & $0.52^{\star *}$ \\
\hline $\mathrm{IL}-1 \beta[\mathrm{pg} / \mathrm{ml}]$ & $1.7 \pm 0.88$ & $1.6 \pm 0.39$ & $0.56^{\star *}$ \\
\hline Procalcitonin $[\mathrm{ng} / \mathrm{ml}]$ & $0.22 \pm 0.29$ & $0.27 \pm 0.46$ & $0.92^{\star *}$ \\
\hline CMV IgG [RU/ml] & $107.02 \pm 86.83$ & $87.41 \pm 62.81$ & $0.67^{* *}$ \\
\hline Leukocytes [G/l] & $6.17 \pm 1.24$ & $7.92 \pm 2.16$ & $0.0002^{\star *}$ \\
\hline Monocytes [G/l] & $0.49 \pm 0.16$ & $0.68 \pm 0.28$ & $0.006^{\star *}$ \\
\hline ESR & $12.46 \pm 6.3$ & $15.7 \pm 7.54$ & $0.079^{\star *}$ \\
\hline Fibrinogen $[\mathrm{g} / \mathrm{l}]$ & $3.24 \pm 0.73$ & $3.68 \pm 0.75$ & $0.012^{*}$ \\
\hline
\end{tabular}

Results presented as mean value $\pm S D$, *Student's t-test, **Mann-Whitney $U$ test

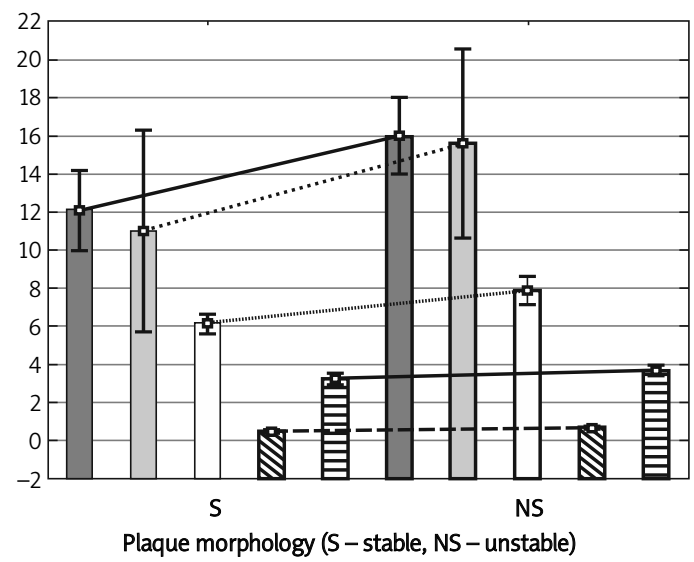

TNF- $\alpha[\mathrm{pg} / \mathrm{ml}] \quad \square$ IL-6 [pg/ml]
$\square-\square$ Leukocytes [G/l]

Figure 2. Inflammatory factors in patients with stable and unstable atherosclerotic plaques

plaque morphology than in patients with stable plaques. The connection of high serum concentrations of IL- 6 and TNF- $\alpha$ with the presence of unstable plaques assessed in ultrasound examinations has been confirmed by other authors as well [15, $25,27]$. In the present study, no significant differences in TNF- $\alpha$ serum levels depending on the presence of stenosis, its level or clinical manifestation were found, which is in agreement with the results obtained by other authors [23, 28].

The participation of IL- 6 in the development of atherosclerotic ICA stenosis was found in a study by Lee et al. [29], in which the serum IL-6 level turned out to be an independent predictive factor of the development of early atherosclerotic lesions in the ICA.

Results from the present study also correspond with results obtained by Debing et al. [30], who found significantly higher serum levels of IL-6 in the group of patients with ICA stenosis in comparison with the control group and no statistically significant differences in IL-6 levels between the group of patients with symptomatic stenosis and the group with asymptomatic stenosis.

The significance of TNF- $\alpha$ and IL- 6 in the development of atherosclerotic lesions was also proven in experimental research on animal models and in in vitro studies [31, 32].

The protective role of IL-10, consisting in the stabilisation of atherosclerotic plaques, was confirmed in immunohistochemical tests of plaques obtained from sections of different arteries, including carotid arteries [33] and in in vivo and in vitro experimental research [34]. The development of atherosclerotic stenosis is a process of active changes, and factors causing the secretion of IL-10 are the same factors that stimulate the production of IL- 6 .

The obtained results also confirm the usefulness of the recognised inflammatory markers (CRP, fibrinogen, ESR, leukocyte count, monocyte count) in the identification of patients with unstable plaques. In recent years, the possibility of using procalcitonin in predicting atherosclerotic complications has been indicated [35]. However, publications concerning assaying serum procalcitonin levels in patients with ICA stenosis are few and do not confirm the usefulness of this marker exceeding the recognised inflammatory markers [36, 37]. In the present study, the connection of procalcitonin level with the presence of unstable ICA stenoses was not confirmed, either. Determination of procalcitonin levels is a test used in clinical practice for diagnosing bacterial infections with a systemic response, which are included among the probable factors participating in the pathogenesis of atherosclerosis $[6,38]$. However, the role of infections of atherosclerotic plaques in their destabilisation has not been unequivocally confirmed $[39,40]$. In the present study, no significant relationship between anti-CMV IgG anti- 
body titre and the presence of unstable stenoses was found.

Changes in the atherosclerotic plaque can be recognised as a chronic inflammatory process. The development of symptoms, and hence the destabilisation of the plaque, is, however, of an acute, rapidly progressing nature. That is why the period from determining cytokine levels to the occurrence of the symptoms may have certain significance when evaluating the level of the examined cytokines, though no significant correlation between the level of the examined cytokines and the time that had passed since the occurrence of the symptoms (more than 14 days) was found. Surgical treatment of internal carotid artery stenosis brings the most benefits in the prevention of vascular incidents when it is carried out within 2 weeks of the occurrence of the clinical symptoms resulting from the presence of this stenosis [19]. Smaller benefits come from using surgical treatment in patients with symptomatic ICA stenosis after a period of 2 weeks of the occurrence of the symptoms and in patients with asymptomatic ICA stenosis. The characteristics of ICA stenosis (the degree of stenosis above $70 \%$ and plaque morphology with the presence of ulcerations on the surface of the plaque and/or a hypoechoic structure of the plaque) were found significantly more often in the group of patients with symptomatic stenosis in comparison with the group of patients with asymptomatic stenosis. These results confirm the usefulness of ultrasound characteristics of instability of ICA stenosis in the evaluation of the risk of the occurrence of clinical symptoms in patients with ICA stenosis [1, 2, 41].

Finding elevated concentrations of some of the discussed inflammatory factors in the serum suggests the presence of unstable plaques, potentially causing danger of the occurrence of clinical symptoms, which may facilitate the qualification of such patients for surgical procedures. In a report by Versaci et al., the intensification of the inflammatory process associated with the presence of active atherosclerotic plaques, represented by an elevated serum concentration of IL-6, was linked with worse results of stenting procedures in patients with advanced ICA stenosis [42].

The confirmation of the role of TNF- $\alpha$, IL- 6 and IL-10 in the development, progression and destabilisation of atherosclerotic ICA lesions allows us to hope that medications that have an effect on the concentration of the examined cytokines may be significant for inhibiting the progression of atherosclerosis. There are interesting reports based on experimental and clinical research regarding the use of anti-cytokine medications (antibodies blocking TNF- $\alpha$ ) in the treatment of atherosclerosis and its complications $[13,14,43]$.
In conclusion, there is a relationship between the activity of the selected inflammatory markers in serum and atherosclerotic unstable internal carotid artery stenosis.

There is no relationship between serum concentration of inflammatory markers and degree of carotid artery stenosis.

\section{References}

1. Biasi GM, Froio A, Diethrich EA, et al. Carotid plaque echolucency increases the risk of stroke in carotid stenting, The Imaging in Carotid Angioplasty and Risk of Stroke (ICAROS) Study. Circulation 2004; 110: 756-62.

2. Biasi GM, Sampaolo A, Mingazzini P, De Amicis P, ElBarghouty N, Nicolaides AN. Computer analysis of ultrasonic plaque echolucency in identifying high risk carotid bifurcation lesions. Eur J Vasc Endovasc Surg 1999; 17: 476-9.

3. Nocuń A, Wilczyński M, Wroński J, Chrapko B. Usefulness of $99 \mathrm{mTc}-\mathrm{ECD}$ brain SPECT with voxel-based analysis in evaluation of perfusion changes early after carotid endarterectomy. Med Sci Monit 2011; 17: CR297-303.

4. Shaalan WE, Cheng H, Gewertz B, et al. Degree of carotid plaque calcification in relation to symptomatic outcome and plaque inflammation. J Vasc Surg 2004; 40: 262-9.

5. Musialek P, Pieniazek P, Tracz W, et al. Safety of embolic protection device-assisted and unprotected intravascular ultrasound in evaluating carotid artery atherosclerotic lesions. Med Sci Monit 2012; 18: MT7-18.

6. Ross R. Atherosclerosis - an inflammatory disease. N Engl J Med 1999; 340: 115-26.

7. Profumo E, Buttari B, Tosti ME, et al. Association of intracellular pro- and anti-inflammatory cytokines in peripheral blood with the clinical or ultrasound indications for carotid endarterectomy in patients with carotid atherosclerosis. Clin Exp Immunol 2008; 152: 120-6.

8. Pelisek J, Rudelius M, Zepper P, et al. Multiple biological predictors for vulnerable carotid lesions. Cerebrovasc Dis 2009; 28: 601-10.

9. Sabeti S, Exner M, Mlekusch W, Amighi J, et al. Prognostic impact of fibrinogen in carotid atherosclerosis: nonspecific indicator of inflammation or independent predictor of disease progression? Stroke 2005; 36: 1400-4.

10. Elkind M, Cheng J, Albala B, Paik M, Sacco R. Elevated white blood cell count and carotid plaque thickness. The Northern Manhattan Stroke Study. Stroke 2001; 32: 842-9.

11. Assayag EB, Bova I, Kesler A, Berliner S, Shapira I, Bornstein NM. Erythrocyte aggregation as an early biomarker in patients with asymptomatic carotid stenosis. Dis Markers 2008; 24: 33-9.

12. Garcia BA, Ruiz C, Chacon P, Sabin JA, Matas M. Highsensitivity C-reactive protein in high grade carotid stenosis: risk marker for unstable carotid plaque. J Vasc Surg 2003; 38: 1018-24.

13. Giaginis C, Klonaris C, Katsargyris A, Kouraklis G, Spiliopoulou C, Theocharis S. Correlation of peroxisome proliferator-activated receptor-gamma (PPAR-gamma) and retinoid $X$ receptor-alpha (RXR-alpha) expression with clinical risk factors in patients with advanced carotid atherosclerosis. Med Sci Monit 2011; 17: CR381-91.

14. Wozniak G, Toska A, Saridi M, Mouzas O. Serotonin reuptake inhibitor antidepressants (SSRIs) against atherosclerosis. Med Sci Monit 2011; 17: RA205-14. 
15. Kablak-Ziembicka A, Przewlocki T, Sokołowski A, Tracz W, Podolec P. Carotid intima-media thickness, hs-CRP and TNF-alpha are independently associated with cardiovascular event risk in patients with atherosclerotic occlusive disease. Atherosclerosis 2011; 214: 185-90.

16. Nishida H, Horio T, Suzuki Y, et al. Interleukin-6 as an independent predictor of future cardiovascular events in high-risk Japanese patients: comparison with C-reactive protein. Cytokine 2011; 53: 342-6.

17. Mallat Z, Besnard S, Duriez M, et al. Protective role of interleukine 10 in atherosclerosis. Circulation Res 1999; 85: 17-24.

18. Grant E, Benson C, Moneta G, et al. Carotid artery stenosis: gray scale and doppler us diagnosis - society of radiologist in ultrasound consensus conference. Radiology 2003; 229: 340-6.

19. Brott TG, Halperin JL, Abbara S, et al. Guideline on the management of patients with extracranial carotid and vertebral artery disease. Circulation 2011; 124: 54-130.

20. Gray-Weale AC, Graham JC, Burnett JR, Byrne K, Lusby RJ. Carotid artery atheroma, comparison of preoperative Bmode ultrasound apperarence with carotid endarterectomy specimen pathology. J Cardiovasc Surg 1988; 29: 676-81.

21. Yamashita H, Shimada K, Seki E, Mokuno H, Daida H. Concentrations of interleukins, interferon, and C-reactive protein in stable and unstable angina pectoris. Am J Cardiol 2003; 91: 133-6.

22. Rajappa M, Sen SK, Sharma A. Role of pro-/anti-inflammatory cytokines and their correlation with established risk factors in South Indians with coronary artery disease. Angiology 2009; 60: 419-26.

23. Koutouzis M, Rallidis LS, Peros G, et al. Serum interleukin-6 is elevated in symptomatic carotid bifurcation disease. Acta Neurol Scand 2009; 119: 119-25.

24. Elkind MS, Cheng J, Boden-Albala B, et al. Tumor necrosis factor receptor levels are associated with carotid atherosclerosis. Stroke 2002; 33: 31-7.

25. Yamagami H, Kitigawa K, Nagai Y, et al. Higher levels of interleukin- 6 are associated with lower echogenicity of carotid artery plaques. Stroke 2004; 35: 677-81.

26. Thakore AH, Guo CY, Larson MG, et al. Association of multiple inflammatory markers with carotid intimal medial thickness and stenosis (from the Framingham Heart Study). Am J Cardiol 2007; 99: 1598-602

27. Edsfeldt A, Dias N, Elmståhl B, et al. Low carotid calcium score is associated with higher levels of glycosaminoglycans, tumor necrosis factor-alpha, and parathyroid hormone in human carotid plaques. Stroke 2011; 42 : 2966-9.

28. Kaperonis EA, Liapis CD, Kakisis JD, Perrea D, Kostakis AG, Karayannakos PE. The association of carotid plaque inflammation and Chlamydia pneumoniae infection with cerebrovascular symptomatology. J Vasc Surg 2006; 44: 1198-204.

29. Lee WY, Allison MA, Kim DJ, Song CH, Barett-Connor E. Association of interleukin- 6 and C-reactive protein with subclinical carotid atherosclerosis (the Rancho Bernardo Study). Am J Cardiol 2007; 99: 99-102.

30. Debing E, Peeters E, Demanet C, De Waele M, Van den Brande $P$. Markers of inflammation in patients with symptomatic and asymptomatic carotid artery stenosis: a case-control study. Vasc Endovascular Surg 2008; 42: $122-7$.

31. Zhang L, Pappel K, Sivashanmugam P, et al. Expression of tumor necrosis factor receptor-1 in arterial wall cells promotes atherosclerosis. Arterioscler Thromb Vasc Biol 2007; 27: 1087-94
32. Huber SA, Sakkinen P, Conze D, Hardin N, Tracy R. Interleukin-6 exacerbates early atherosclerosis im mice. Arterioscl Thromb Vasc Biol 1999; 19: 2364-7.

33. Mallat Z, Heymes CH, Ohan J, Faggin E, Leseche G, Tedgui $A$. Expression of interleukin-10 in advanced human atherosclerosic plaques. Relation to inducible nitric oxide synthase expression and cell death. Arterioscl Thromb Vasc Biol 1999; 19: 611-6.

34. Potteaux S, Esposito B, van Oostrom O, et al. Leukocytederived interleukin 10 is required for protection against atherosclerosis in low-density lipoprotein receptor knockout mice. Arterioscler Thromb Vasc Biol 2004; 24 1474-8.

35. Brunkhorst FM, Eberhard OK, Brunkhorst R. Discrimination of infectious and noninfectious causes of early acute respiratory distress syndrome by procalcitonin. Crit Care Med 1999; 27: 2172-6.

36. Mommertz G, Langner S, Koppel T, et al. The role of procalcitonin as predictor for neurological deficits after carotid endarterectomy. J Cardiovasc Surg 2009; 50: 665-8.

37. Sinning CR, Sinning JM, Schulz A, et al.; Athero Gene Study Investigators. Association of serum procalcitonin with cardiovascular prognosis in coronary artery disease. Circ J 2011; 75: 1184-91.

38. Makris GC, Makris MC, Wilmot VV, Geroulakos G, Falagas ME. The role of infection in carotid plaque pathogenesis and stability: the clinical evidence. Curr Vasc Pharmacol 2010; 8: 861-72.

39. Halvorsen DS, Karlsen J, Notø AT, et al. No detectable Chlamydia pneumoniae and cytomegalovirus DNA in leukocytes in subjects with echolucent and echogenic carotid artery plaques. Int J Cardiol 2007; 117: 388-94.

40. Chiu B, Viira E, Tucker W, Fong IW. Chlamydia pneumoniae, cytomegalovirus, and herpes simplex virus in atherosclerosis of the carotid artery. Circulation 1997; 96: 2144-8.

41. Nicolaides AN, Kakkos SK, Griffin M, et al. Asymptomatic Carotid Stenosis and Risk of Stroke (ACSRS) Study Group. Severity of asymptomatic carotid stenosis and risk of ipsilateral hemispheric ischaemic events: results from the ACSRS study. Eur J Vasc Endovasc Surg 2005; 30: 275-84.

42. Versaci F, Reimers B, Prati F, et al. Prediction of cardiovascular events by inflammatory markers in patients undergoing carotid stenting. Mayo Clin Proc 2012; 87: 50-8

43. Atzeni F, Turiel M, Caporali R, et al. The effect of pharmacological therapy on the cardiovascular system of patients with systemic rheumatic diseases. Autoimmun Rev 2010; 9: 835-9. 